\title{
USO DE LÍQUENS NO MONITORAMENTO DA QUALIDADE DO AR NO MUNICÍPIO DE CAÇAPAVA DO SUL
}

\author{
Jauana Marilise do Nascimento Riegel - riegel.jauana@gmail.com \\ Universidade Federal do Pampa - UNIPAMPA
}

Pedro Daniel da Cunha Kemerich - eng.kemerich@ yahoo.com.br

Universidade Federal do Pampa - UNIPAMPA 


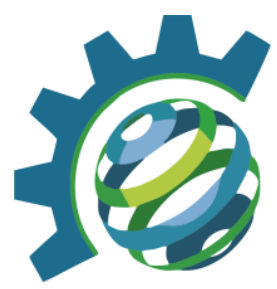

\section{RESUMO}

Tendo em vista a degradação da qualidade do ar faz-se necessário o monitoramento da ambiental de regiões com intensa ação antrópica, gerada dentre outros motivos pela exploração mineral, trafego veicular e a emissão de $\mathrm{CO} 2$ ao ar atmosférico, proveniente da utilização demasiada de lenha em lareiras e fogões em períodos mais frios como o outono e inverno. Deste modo, ocasionando o excesso de material particulado no ar atmosférico, com diferentes concentrações e composições químicas. Convenientemente há maneiras de monitorar a qualidade do ar por meio de organismos vivos nomeados como bioindicadores. Os liquens são utilizados como bioindicadores devido a sua excessiva sensibilidade aos componentes tóxicos do ar e sua vasta capacidade de acumular elementos. Adequadamente, o monitoramento é dado devido a intervenção da concentração dos elementos absorvidos pelos líquens, diante de suas alterações fisiológicas, morfológicas e genéticas. A reação do organismo às agressões externas é avaliada perante suas modificações nos ciclos vitais. A metodologia empregada neste estudo compreendeu em três etapas: i) Planejamento para implantação dos bioindicadores; ii) Coleta e avaliação dos dados; iii) Processamento e interpretação dos dados coletados, com o auxílio do método analítico de espectrometria de fluorescência de raios-X. Onde foi possível qualificar e quantificar os elementos existentes nesses organismos em decorrência da bioacumulação. Após as analise notou-se o intenso acumulo de $\mathrm{Ca}, \mathrm{Mg}$ e $\mathrm{Si}$, no qual a presença destes elementos está fortemente ligada às estruturas geológicas presentes em rochas graníticas ácidas (maior que $65 \%$ de $\mathrm{SiO}_{2}$.) e lentes de calcário dolomítico. O beneficiamento do calcário dolomítico realizado pelas mineradoras locais contribuí para a dispersão do $\mathrm{Ca}$ e $\mathrm{Mg}$ na atmosfera, pois a mesma compreende em sua composição entre 30-35\% de $\mathrm{CaO}$ e 15-20\% MgO. Após este estudo foi possível compreender o comportamento espacial e temporal dos contaminantes no perímetro urbano da cidade de Caçapava do Sul, dando subsídios as tomadas de decisão oriundas das empresas geradoras e do poder público com vistas a garantir a manutenção da saúde pública.

Palavras-chave: Biomonitoramento, Espectrometria de fluorescência de raios-X, Mineração

\section{INTRODUÇÃO/OBJETIVO}

O estudo sobre qualidade do ar se faz de suma importância como representada pelo Art. $1^{\mathrm{o}}$ previsto na Resolução CONAMA $\mathrm{n}^{\mathrm{o}}$ 05, de 15.06 .89 , determinando padrões de qualidade do ar para as concentrações de poluentes atmosféricos que, ultrapassadas, poderão afetar a saúde, a segurança e o bem-estar da população, bem como ocasionar danos à flora e à fauna, aos materiais e ao meio ambiente em geral. Sendo classificados como poluentes atmosférico "qualquer forma de matéria ou energia com intensidade e em quantidade, concentração, tempo ou características em desacordo com os níveis estabelecidos (...)” (Brasil, 1990). De modo a classificar os poluentes em materiais particulados presentes na atmosfera podendo ser nocivo ou ofensivo a saúde, Braga et al. (2002) destaca que esses materiais são classificados sendo poluentes primários, quando emitidos diretamente pela fonte poluidora, e em poluentes secundários, quando formados a partir de reações entre os poluentes primários e os componentes naturais da atmosfera. 


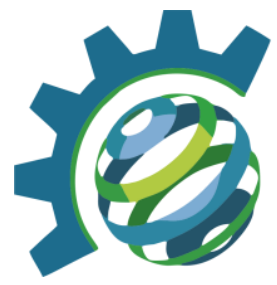

Contudo, é importante ressaltar a influência sobre as atividades antrópicas com o produto da interação de um complexo conjunto de fatores dentre os quais destacam-se a magnitude das emissões, a topografia e as condições meteorológicas da região, favoráveis ou não à dispersão dos poluentes. Segundo estudos epidemiológicos elaborados pelo Ministério do Meio Ambiente (MMA) demonstrando a correlações entre a exposição aos poluentes atmosféricos e os efeitos de morbidade e mortalidade, causadas por problemas respiratórios (asma, bronquite, enfisema pulmonar e câncer de pulmão) e cardiovasculares, mesmo quando as concentrações dos poluentes na atmosfera não ultrapassam os padrões de qualidade do ar vigentes. Deste modo as populações mais vulneráveis são as crianças, os idosos e as pessoas que já apresentam doenças respiratórias. Além de prejuízos a saúde e a qualidade de vida, a poluição também acarreta a maiores gastos do estado decorrentes do aumento do número de atendimentos e internações hospitalares e gastos com medicamentos. A poluição de ar pode também afetar ainda a qualidade dos materiais pela corrosão, podendo influenciar na composição do solo e das águas ocasionando possíveis chuvas ácidas, além de afetar a visibilidade.

Uma das metodologias que vêm sendo amplamente utilizada em vários países é o uso de organismos vivos denominados bioindicadores como por exemplo os musgos liquens e vegetais superiores para detectar os níveis de poluentes na atmosfera dos centros urbanos. (Hawksworth 2005; Klumpp et al. 1998). A utilização de bioindicadores consiste numa alternativa cada vez mais utilizada para o acompanhamento da qualidade do ar atmosférico. Este pode ser descrito como sendo um método experimental indireto que permite a verificação da existência de poluentes em uma área determinada através do uso de organismos vivos que respondem ao estresse a que se encontram submetidos por modificações nos ciclos vitais ou pela acumulação de poluentes (Carneiro, 2004; Nogueira, 2006). Desta forma a capacidade de colonização está relacionada a estratégias químicas e fisiológicas de sobrevivência a diferentes ambientes. Já o sucesso ecológico dos liquens tem sido associado aos metabólitos secundários sintetizados e acumulados em seus talos. A resposta pode ser verificada pela determinação de parâmetros que indicam alterações fisiológicas morfológicas genéticas ou ainda podem ser usados como monitores acumulativos de poluentes persistentes (Loppi et al. 2004). O transplante de espécies liquênicas de áreas rurais não poluídas para regiões onde haja um nível de poluição mais elevado é um método ecofisiológico de estudo de campo sobre a ação de poluentes presentes na atmosfera que serve ainda como confirmação das experiências realizadas em laboratório com a mesma finalidade (Le Blanc and Rao 1975).

\section{METODOLOGIA}

\subsection{Caracterização da Área em Estudo}

O município de Caçapava do Sul possui uma área total de $3.047 .113 \mathrm{~km}^{2}$ (Conforme a figura 1) e população de 34.654 (IBGE 2015), possuindo uma frota de veicular de 18.837 automóveis (IBGE2016). Apresenta uma densidade demográfica de 11,06 hab./ $\mathrm{km}^{2}$. Onde a renda per capta é 18.021,00 (IBGE 2013). Sendo o beneficiamento pela exploração mineral, o principal responsável pela produção de calcário no Rio Grande do Sul, responsável por $80 \%$ da 

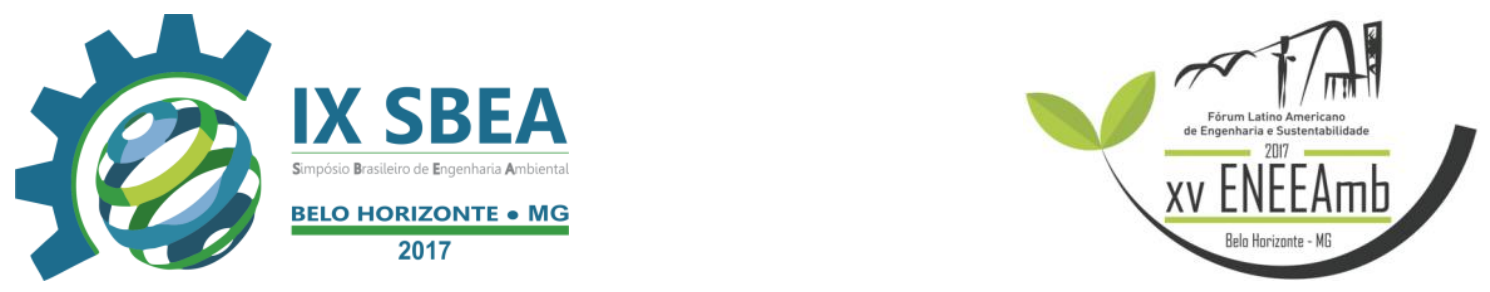

produção no estado. A economia municipal é baseada fortemente no setor primário, contando com agricultura e pecuária, visando sua extensão territorial com terras rurais. A cidade pertence a macrorregião Sul do país e mesorregião do Sudeste Rio-Grandense, inserida na microrregião das Serras de Sudeste.

Figura 1 - Mapa de situação e localização da área de estudo, no município de Caçapava do Sul/RS.
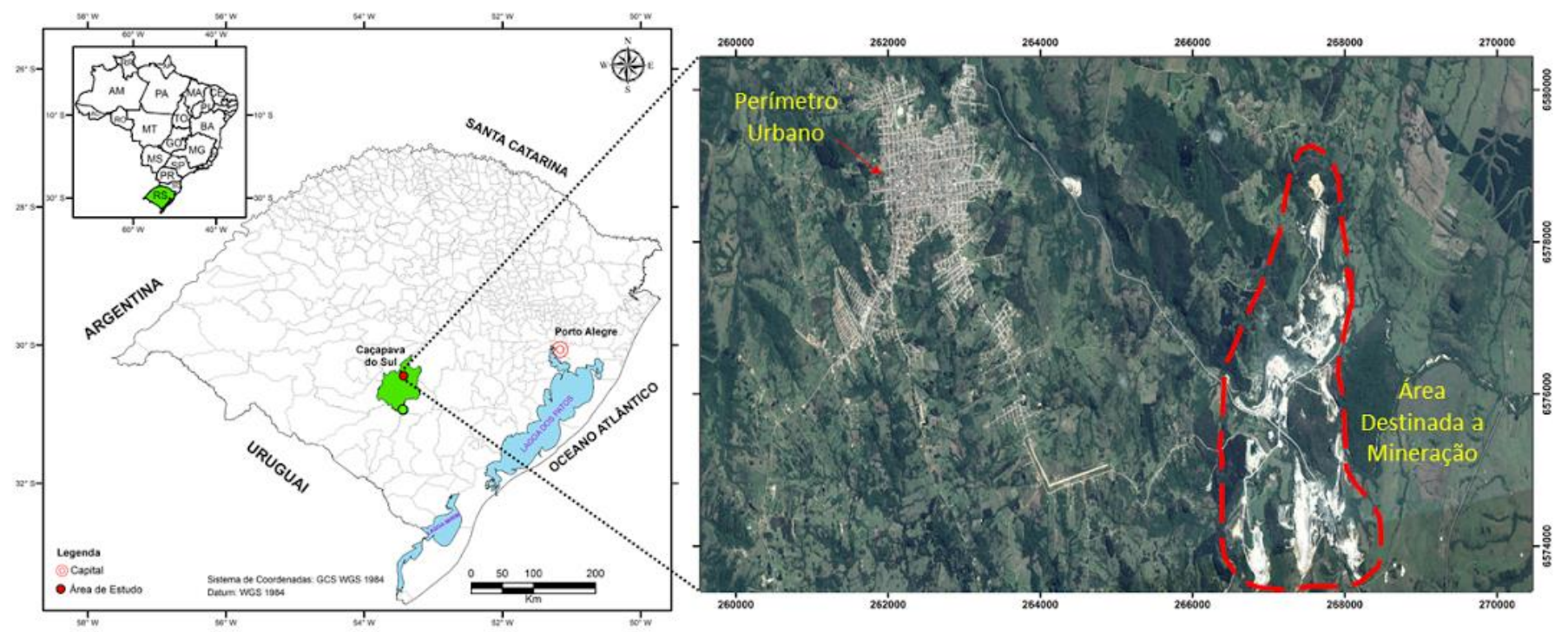

Os pontos de monitoramento da qualidade do ar foram dispostos de modo a identificar a influência da exploração mineral nas alterações dos padrões de qualidade ambiental, conforme a Figura 2. O primeiro ponto (P1) foi colocado na área industrial conhecida como Caieiras onde localizam-se as sete mineradoras de calcário de Caçapava do Sul. Outros três pontos foram dispostos estrategicamente em áreas que possuem maior tráfego veicular. Sendo o ponto três (P3) colocado na rotula que faz a ligação entre a entrada da cidade pela BR-392 com a Universidade Federal do Pampa, tendo em vista a intensa circulação de caminhões e carros neste ponto. $\mathrm{O}$ quarto ponto de monitoramento (P4) foi disposto na rotula que liga a Avenida Presidente Kennedy com Avenida Benjamin Constant. Do mesmo modo, o ponto cinco (P5) foi colocado na esquina que dá acesso pela Avenida Benjamin Constant à Rua XV de novembro. O último ponto (P2) foi colocado no Forte Dom Pedro II, onde não há trafego intenso de veículos contando com uma área ambientalmente preservada em meio urbano. 

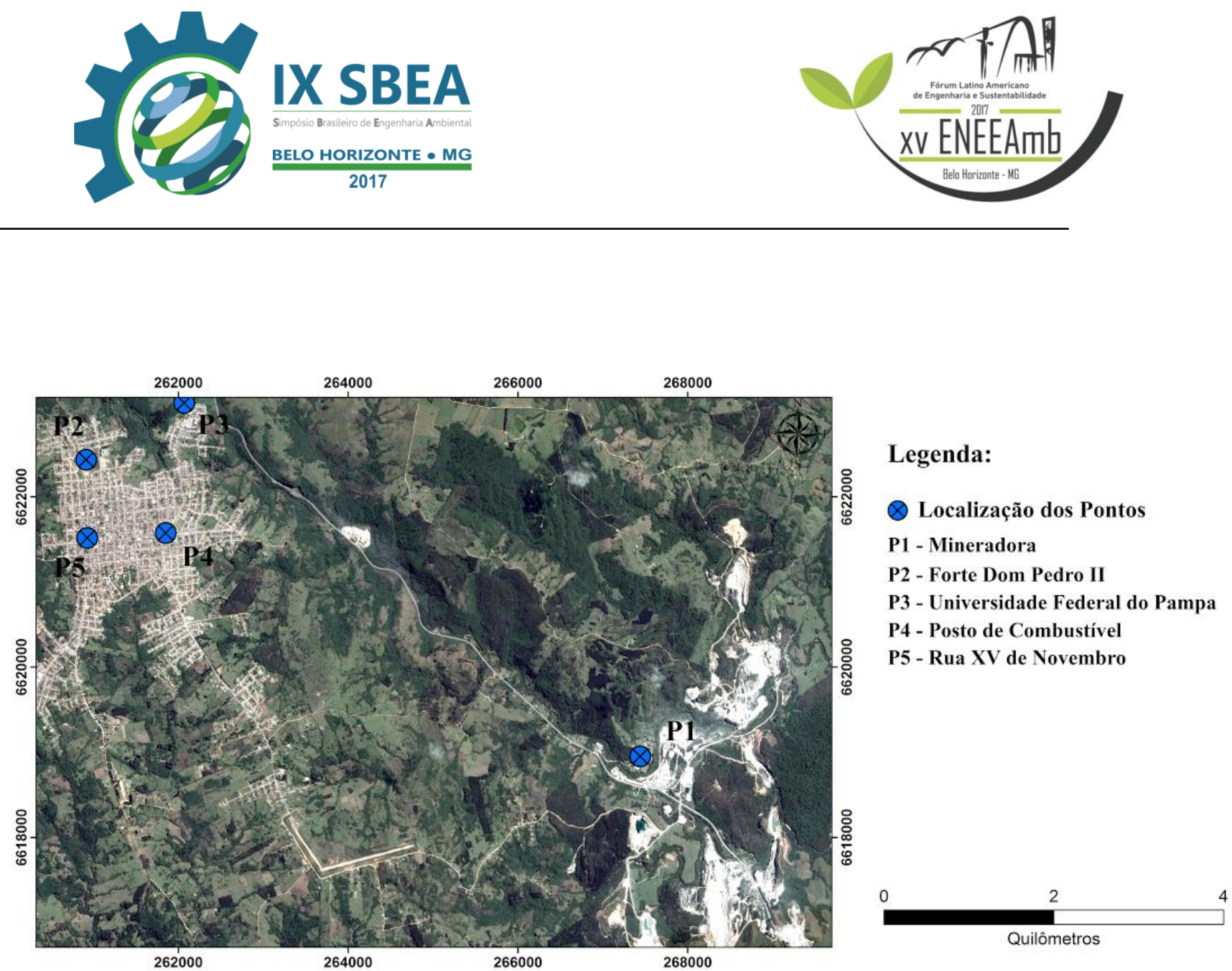

Figura 2 - Localização espacial dos pontos para coleta e amostragem dos dados.

\subsection{Bioindicadores Utilizados}

Para a elaboração do estudo foi utilizado os líquens do Gênero Usnea. Segundo Halonen et al. 1999, as espécies ocorrem preferencialmente em locais úmidos e bem iluminados, desde o nível do mar até altitudes mais elevadas. São encontradas sobre árvores e arbustos, e raramente em rochas (Clerc \& Herrera-Campos 1997). Conforme Marcelli (1998), no Brasil a diversidade do gênero pode ser alta nas regiões mais úmidas e de maiores altitudes.

\subsection{Transplante e exposição das amostras}

As amostras de líquens foram coletadas em uma área natural preservada, localizada na zona rural do município de Caçapava do Sul. Os bioindicadores foram colocados de forma estratégica, sendo amarrados em árvores com a utilização de fios dentais previamente lavados com água destilada (buscando-se a eliminação de possíveis substâncias que possam interferir nos resultados) a aproximadamente 1,7 metros de altura, desse modo padronizando a altura de exposição evitando perdas e furtos. Os líquens ficaram expostos durante toda estação de primavera no ano de 2016 e verão de 2016/2017.

\subsection{Determinações Analíticas}

A coleta e avaliação dos dados foi feita de acordo com a mudança de estação Primavera-Verão. Onde ocorreu a troca dos líquens para analise com o auxílio do espectrômetro de fluorescência de raios-x da marca Bruker, modelo S1 Turbo SD. Os líquens foram analisados -em duas etapas; inteiros e macerados. Onde após analises foi possível através da realização de 

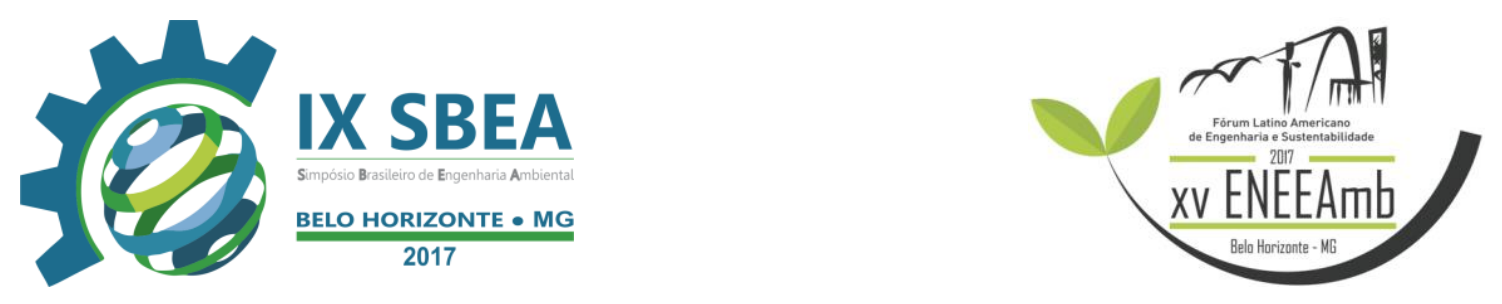

triplicata para cada leitura por espectrometria, para que assim fosse possível estabelecer o desvio padrão e media referente às concentrações.

O equipamento ED-X (Figura 3) é composto por um tubo de raio-X do tipo cerâmica metálica de $1 \mathrm{~W}$ que vai de 2 a $60 \mu \mathrm{A}$. Utiliza-se um ânodo de Ag, que permite a medição de 25 elementos proporcionando análise elementar rápida e precisa, sendo capaz de detectar elementos como alumínio $(\mathrm{Al})$, magnésio $(\mathrm{Mg})$, cobre $(\mathrm{Cu})$, chumbo $(\mathrm{Pb})$, mercúrio $(\mathrm{Hg})$, cádmio $(\mathrm{Cd})$, bromo $(\mathrm{Br})$, entre outros, em nível de ppm. Possui um detector SDD (Silicon Deriva Detector) de $10 \mathrm{~mm}^{2}$ com refrigeração termoelétrica, com uma resolução de $\sim 145 \mathrm{eV}$ a $\mathrm{MnK} \alpha$, o que permite manter uma velocidade de contagem 100.000 contagens por segundos (BAZAES,2013). O equipamento gera um relatório com os resultados das concentrações e o desvio padrão. Para isto, em cada análise o equipamento realiza três leituras. Os valores obtidos serão comparados com os valores de referência e portarias dos órgãos ambientais competentes.

\subsection{Variação Espacial das Concentrações}

Para o processamento e interpretação dos dados visando a espacialização o dos resultados obtidos foram utilizados os Softwares ArcGIS-ArcMap 10.3, onde inicialmente foram lançados os valores para cada ponto de amostragem com as coordenadas UTM (Universal Transversa de Mercator) sendo utilizados para confecção dos mapas do trabalho. Contudo, utilizando o interpolador IDW - Ponderação do inverso da distância foi possível efetuar a modelagem dos dados.

\section{RESULTADOS E DISCUSSÃO}

Nas Tabelas 1 e 2 são mostrados os resultados obtidos com as determinações analíticas realizadas em amostras de liquens Usnea retirados dos pontos de amostragem nas estações primavera- verão no ano de 2016 ao ano de 2017.

Tabela 1: Concentrações de Magnésio ( $\mathrm{Mg}$ ), silício ( $\mathrm{Si}$ ) e cálcio $(\mathrm{Ca})$ em liquens retirados dos cinco pontos de amostragem após sua exposição durante a Primavera de 2016.

\begin{tabular}{cccc}
\hline Local de Amostragem & $\mathrm{Mg}(\mathrm{mg} \mathrm{kg} \mathrm{-1})$ & $\mathrm{Si}(\mathrm{mg} \mathrm{kg} \mathrm{-1})$ & $\mathrm{Ca}(\mathrm{mg} \mathrm{kg} \mathrm{-1})$ \\
\hline P1 & $3,913 \pm 1,021$ & $1,693 \pm 0,839$ & $5,523 \pm 0,752$ \\
P2 & $3,690 \pm 0,864$ & $4,996 \pm 1,347$ & $3,430 \pm 1,929$ \\
P3 & $3,016 \pm 0,624$ & $6,176 \pm 3,040$ & $1,950 \pm 0,712$ \\
P4 & $2,506 \pm 0,391$ & $7,866 \pm 6,974$ & $5,136 \pm 1,549$ \\
P5 & $1,876 \pm 0,322$ & $1,356 \pm 0,574$ & $7,553 \pm 5,136$ \\
\hline
\end{tabular}

Tabela 2: Concentrações de Magnésio $(\mathrm{Mg})$, silício ( $\mathrm{Si}$ ) e cálcio (Ca) em liquens retirados dos cinco pontos de amostragem após sua exposição durante o verão de 2016/2017. 

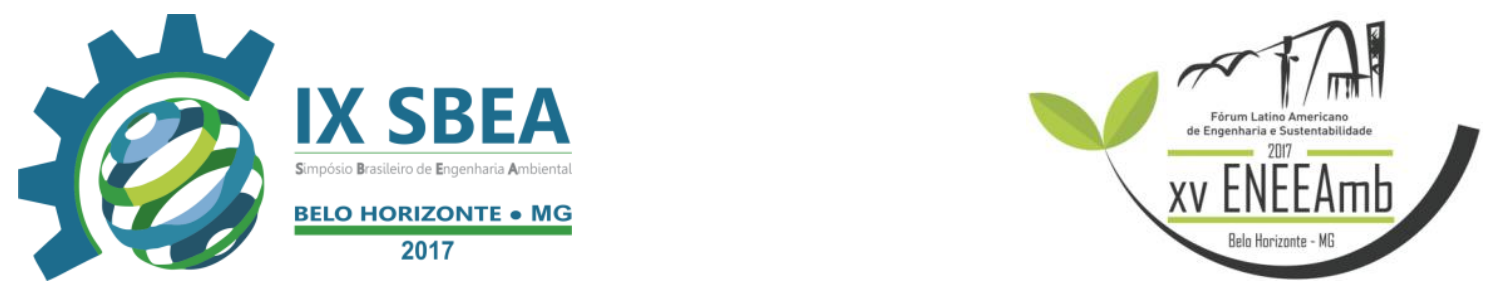

\begin{tabular}{cccc}
\hline Local de Amostragem & $\mathrm{Mg}(\mathrm{mg} \mathrm{kg} \mathrm{-1})$ & $\mathrm{Si}(\mathrm{mg} \mathrm{kg} \mathrm{-1})$ & $\mathrm{Ca}(\mathrm{mg} \mathrm{kg} \mathrm{-1})$ \\
\hline P1 & $3,686 \pm 1,422$ & $1,296 \pm 1,021$ & $5,923 \pm 0,959$ \\
P2 & $2,936 \pm 0,885$ & $4,713 \pm 0,863$ & $3,343 \pm 1,091$ \\
P3 & $2,406 \pm 1,972$ & $2,406 \pm 1,296$ & $3,996 \pm 0,558$ \\
P4 & $2,263 \pm 1,631$ & $4,810 \pm 1,529$ & $4,086 \pm 1,101$ \\
P5 & $1,276 \pm 0,902$ & $3,023 \pm 1,071$ & $5,113 \pm 1,982$ \\
\hline
\end{tabular}

a)
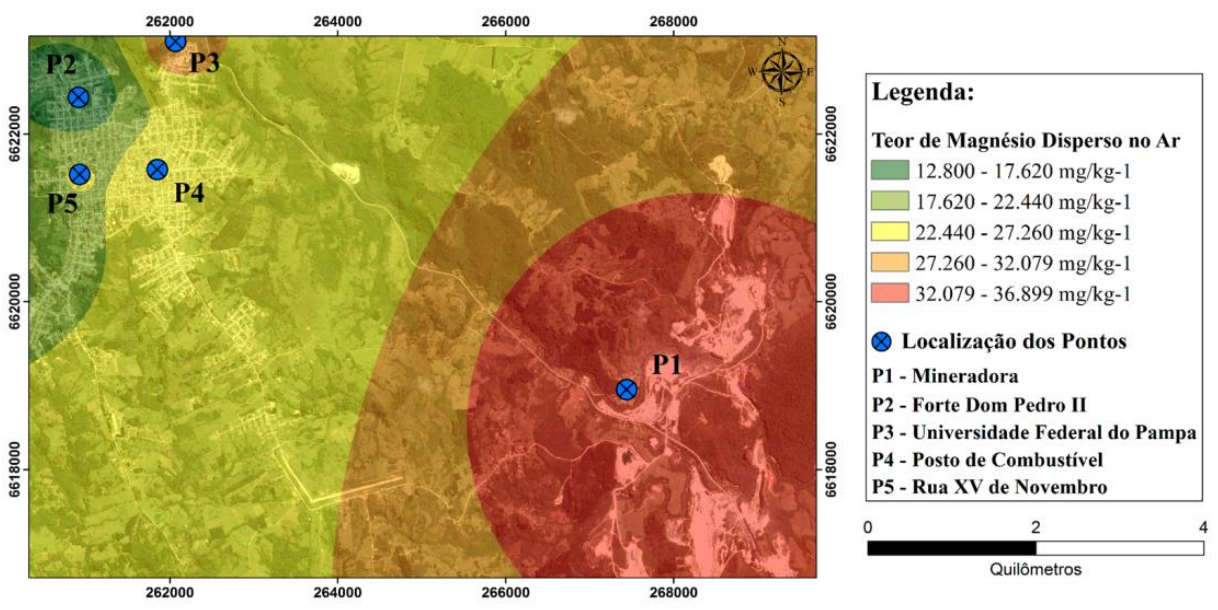

b)

262000

264000

266000

268000
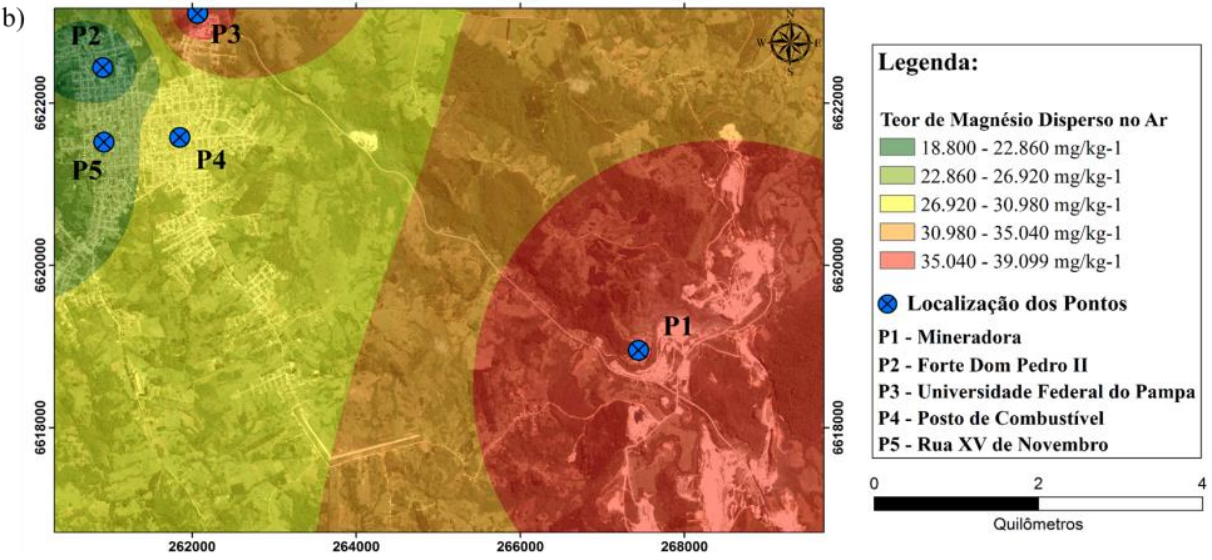

Figura 3 - Mapas de dispersão do magnésio no ar no perímetro urbano do município de Caçapava do Sul, em a) durante a estação do verão e b) durante a estação da primavera.

Através da análise dos mapas e a correlação principalmente com a geologia local, podemos notar que próximo a região onde ocorre a exploração mineral do calcário, notamos uma intensa dispersão de magnésio no ar. Esse elemento é proveniente do calcário dolomítico, característico da região de Caçapava do Sul, com teores entre 18 a $25 \%$ de óxido de magnésio (MgO) (BENEDETTI, 2006). Muito utilizado para correção de solos ácidos na agricultura, comumente encontrado nessa região do estado. 

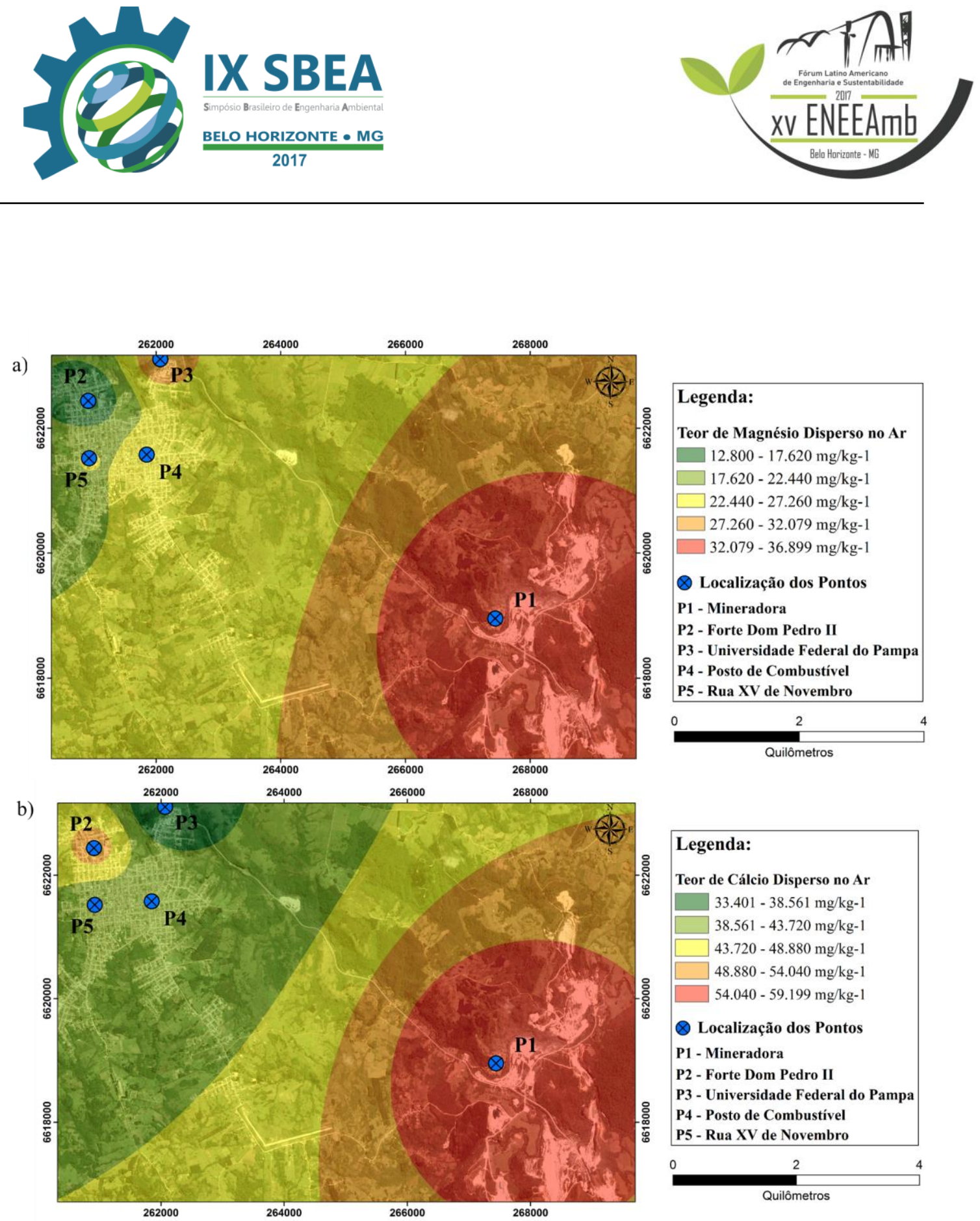

Figura 4 - Mapas de dispersão do cálcio no ar no perímetro urbano do município de Caçapava do Sul, em a) durante a estação da primavera e b) durante a estação do verão.

Os mapas acima nos fornecem uma notável correlação da mineração de calcário com dispersão de cálcio. Análises químicas realizadas com amostras de diferentes mineradoras locais, indicam que mais de $30 \%$ dessa litologia é composta por óxido de cálcio (Cao) (BENEDETTI, 2006). 

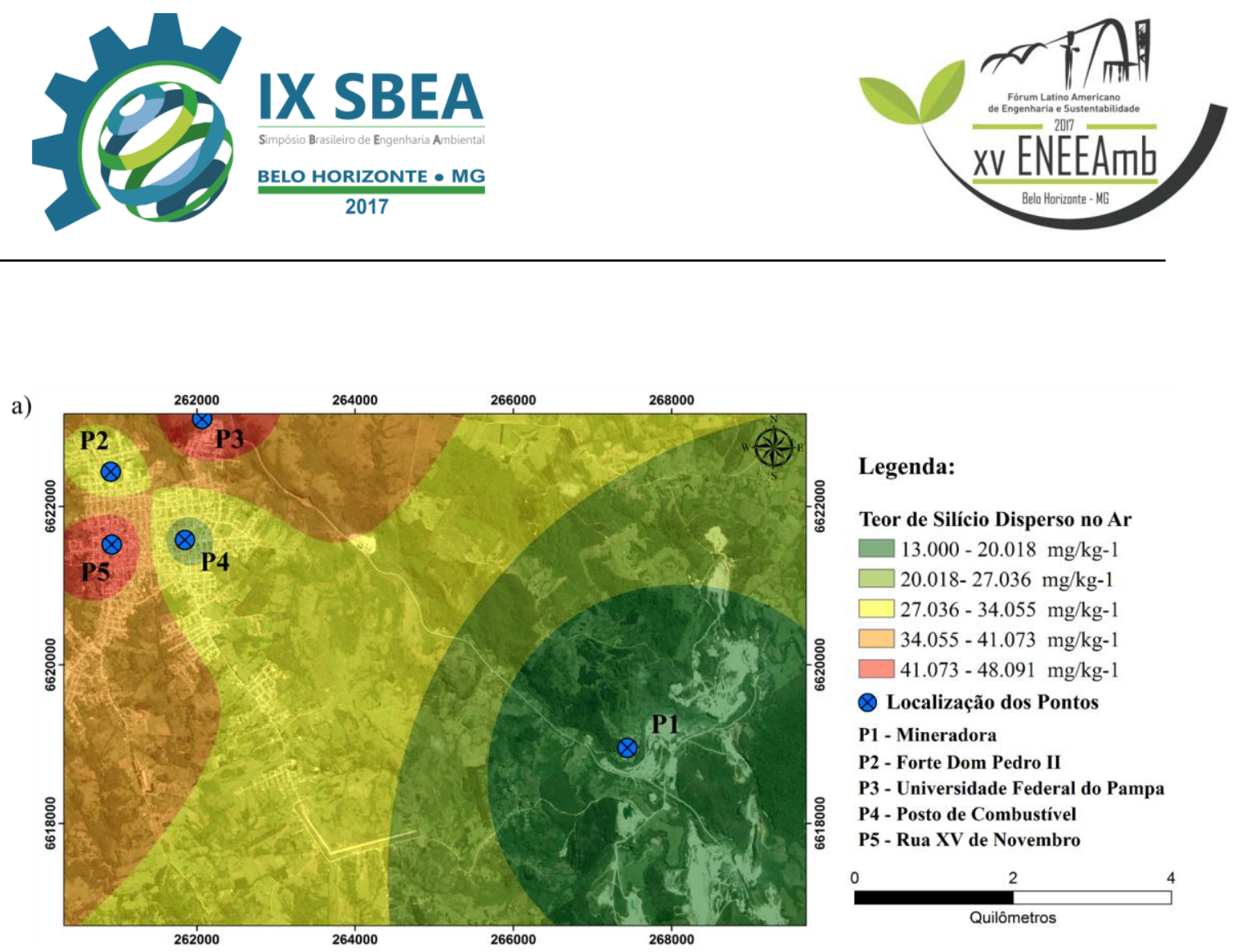

Legenda:

Teor de Silício Disperso no Ar

$\square 13.000-20.018 \mathrm{mg} / \mathrm{kg}-1$

$\square$ 20.018- $27.036 \mathrm{mg} / \mathrm{kg}-1$

$\square 27.036-34.055 \mathrm{mg} / \mathrm{kg}-1$

$\square 34.055-41.073 \mathrm{mg} / \mathrm{kg}-1$

$\square 1.073-48.091 \mathrm{mg} / \mathrm{kg}-1$

Q Localização dos Pontos

P1 - Mineradora

P2 - Forte Dom Pedro II

P3 - Universidade Federal do Pampa

P4 - Posto de Combustível

P5 - Rua XV de Novembro

b)
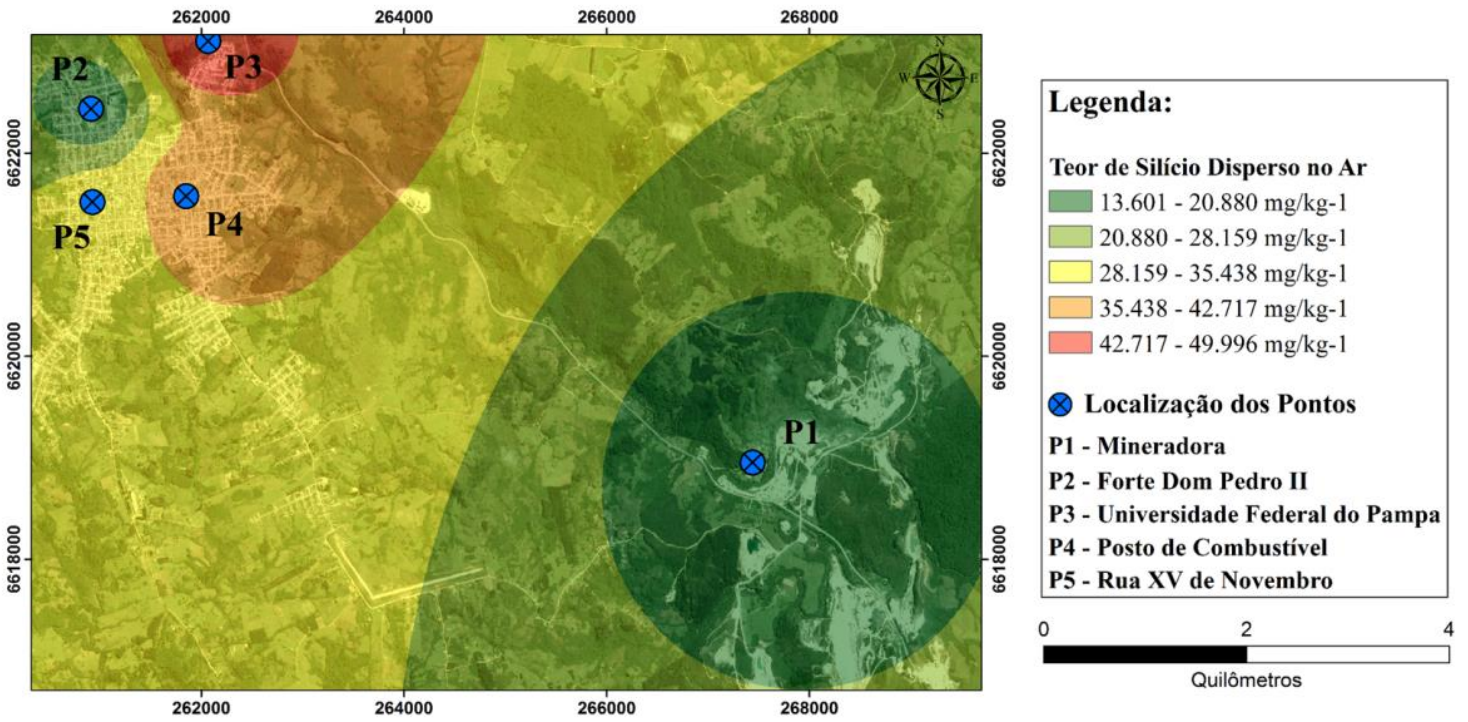

Figura 5 - Mapas de dispersão do silício no ar no perímetro urbano do município de Caçapava do Sul, em a) durante a estação do verão e b) durante a estação da primavera.

A análise dos mapas de isovalores de silício, nos indicam que o perímetro urbano de Caçapava do Sul encontra-se nos valores extremos da dispersão de silício. As causas maiores para esses valores extremos nessa área, estão relacionadas ao intenso fluxo automotivo.

Outro fator que causa tal fenômeno, deve-se ao intemperismo das rochas em que a cidade está situada acima. Caçapava do Sul está inserida sobre uma suíte granítica, onde a sílica $\left(\mathrm{SiO}_{2}\right)$, compõe mais de $65 \%$ dessa rocha.

\section{CONCLUSÕES/RECOMENDAÇÕES}

As maiores concentrações dos elementos determinados foram encontradas nas amostragens realizadas nos pontos de amostragem P1 e P3. Estes locais são caracterizados por intenso trafego veicular e possuindo intensa exploração mineral, que as torna mais susceptíveis 

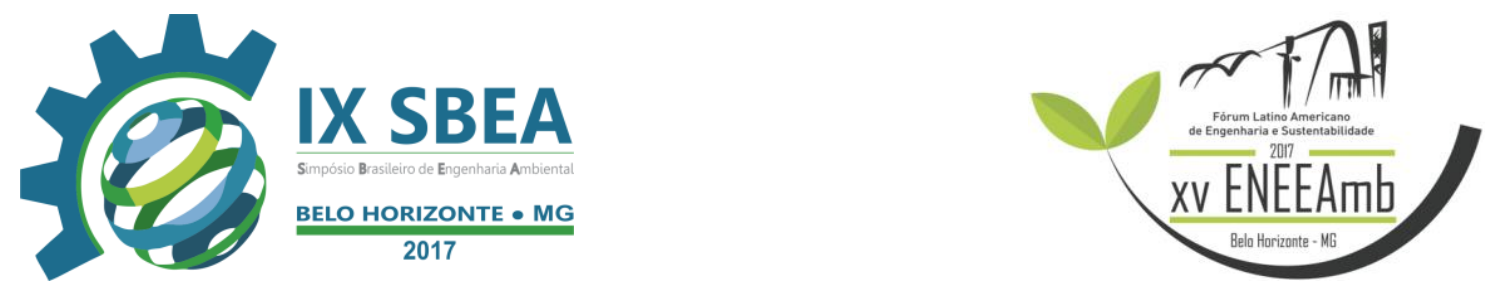

à acumulação de poluentes atmosféricos. O gênero Usnea mostrou-se um bom bioindicador de elementos presentes no ar atmosférico, permitindo o estudo de três diferentes elementos químicos na área em estudo através das diferenças de concentração entre os pontos de amostragem e em comparação aos níveis de acumulação destes em liquens de área preservada. Pode-se concluir também que, de uma forma geral, o ar atmosférico da área urbana de Caçapava do Sul é afetado pela exploração mineral ocasionando danos à saúde pública e ao meio ambiente.

\section{REFERÊNCIAS}

BRASIL. Conselho Nacional de Meio Ambiente, CONAMA. Resolução $n^{\circ} 03$ de 28 de junho de 1990

BRAGA, B.; HESPANHOL, I.; CONEJO, J.G.L.; BARROS, M.T.L. DE; VERAS JUNIOR, M.S. O meio atmosférico. In: __ Introdução a Engenharia Ambiental. São Paulo: Editora Printice Hall, Cap. 10. p. 169-214, 2002

BAZAES CASANOVA, Aliosha Andro W. Comparación de corrección teórica de efecto matriz, análisis de interferencias y corrección por compensación para equipos portátiles de fluorescencia de rayos x en minerales y suelos. 2013.

DOS SANTOS, Eliane Pereira et al. USO DE LIQUENS E DA TÉCNICA DE ESPECTROMETRIA DE FLUORESCÊNCIA DE RAIOS-X POR ENERGIA DISPERSIVA PARA MONITORAMENTO DA QUALIDADE DO AR. Geociências (São Paulo), v. 33, n. 1, p. 61-72, 2014.

DA CUNHA KEMERICH, Pedro Daniel et al. Biomonitoramento e variabilidade espacial do dióxido de enxofre em ar urbano/Biomonitoring and spatial variability of sulphur dioxide in urban air. Revista Ambiente \& Água, v. 6, n. 3, p. 210, 2011.

HAWKSWORTH D. L. The long-terms effects of air pollutants on lichen communities in Europe and North America. In: WOODWELL G. M. (ed.). Pattern and processes of biotic impoverismente. Cambridge: Cambridge University Press 1992. p. 45-64.

HAWKSWORTH D. L. Mycological research news. Mycology Research v. 109 n. 9 p. 9619632005

IBGE. Instituto Brasileiro de Geografia e Estatística. Censo Demográfico, 2015.

LE BLANC F.; RAO D. N. Effects of pollutants on lichens and bryophytes. In: MUDD J.

KOZLOWSKI T. T. Responses of plant to air pollution. London: Academic Press 1975. p. 237 - 272. Cap. 11.

LOPPI S.; FRATI L.; PAOLI L.; BIGAGLI V.; ROSSETTI C.; BRUSCOLI C. et al. Biodiversity of epiphytic lichens and heavy metal contents of Flavoparmelia caperata. 